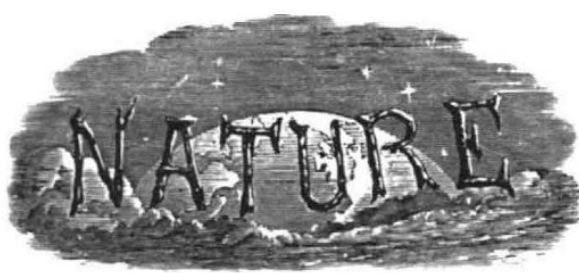

SATURDAY, NOVEMBER 26, 1932

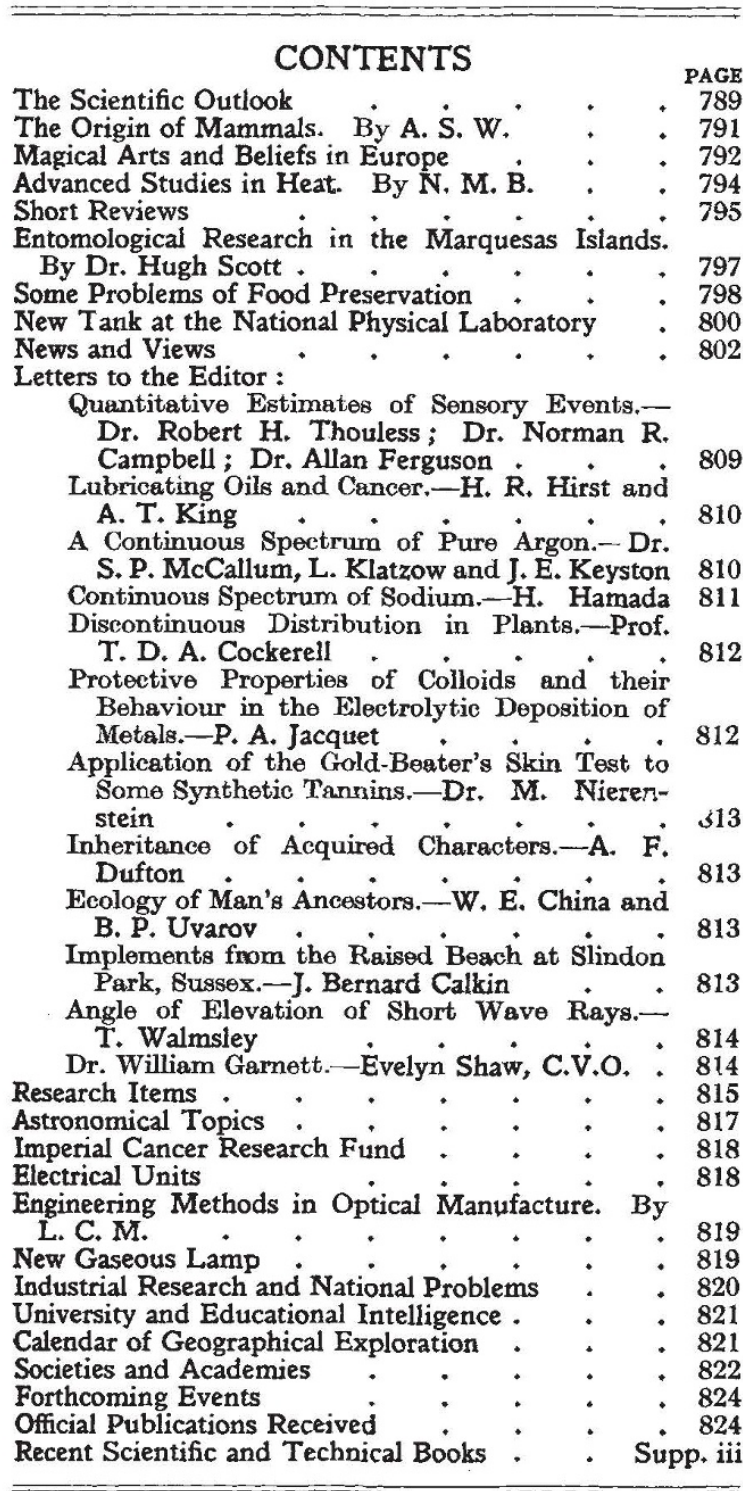

Editorial and Publishing Offices :

MACMILLAN \& CO., LTD.

ST. MARTIN'S STREET, LONDON, W.C. 2

Telephone Number: WHITEHALL 8831

Telegraphic Address: PHUSIS, LESQUARE, LONDON

Advertisements should be addressed to

T. G. Scott \& Son Ltd., 63 Ludgate Hill, London, E.C.4

Telephone Number : City 1266

\section{The Scientific Outlook}

T $T$ might have been expected that two such addresses as those delivered by Sir Alfred Ewing and Prof. Miles Walker at the York meet. ing of the British Association would have provoked a storm of criticism. Much of the criticism has, however, been directed at the details of the scheme proposed by Prof. Miles Walker, and some of the critics have assumed that his address advocated the participation in government of the engineer as distinct from other scientific workers, or indeed from those possessing a scientific outlook or the capacity to assess technical and scientific factors. Few of the critics have revealed any appreciation of the difficulties with which mass production confronts our civilisation or the moral weakness of man as compared with his tremendous command over natural forces.

The fact that both addresses were delivered by engineers has made it easier for prejudice to obscure the real issues by representing the addresses as sectarian clamourings for greater power. The fundamental challenge which they issue to the present order was ignored and it was left for Prof. J. L. Myres, at the Oxford meeting of the Association of Special Libraries and Information Bureaux, in an address on "Science and the Humanities", to direct attention to this challenge. Prof. Miles Walker's address does not so much outline an experiment in sociology, an attempt to relate knowledge and power more effectively and to eliminate prejudice, as offer a challenge to the general outlook of to-day, the poverty of which is one of our most serious troubles. Men have assumed too easily that the present depression will be ended by the old methods and that a return to prosperity will come without special effort.

Two things are involved in any such effort, on both of which Prof. Miles Walker touches: accurate knowledge of the changes which are taking place in our civilisation as a result of the application of scientific discoveries, and particularly of the consequences of power production and of the increased means of communication, whether in the sense of transport or of intelligence such as in broad. casting; and secondly, the training which must now be given to people in this age to render them competent to live.

It is at this point that we reach the essential challenge to modern politics, economics and education implicit in the last part of Sir Alfred Ewing's address. What society must inevitably

No. 3291, Vor. 130] 
consider is the relative value of science and the humanities both in the organisation and development of the world order and in the preparation of the individual members to enjoy the privileges and discharge the responsibilities inherent in membership of a society based on scientific achievements. The criticism of the scientific training given by our existing educational system, which came from Prof. Miles Walker, is supported by similar criticism from many other quarters; in neither education, politics nor economics is it wise to assume that our present institutions will stand the test without radical transformation.

The relative contribution of science and the humanities at this juncture of national or world affairs cannot be determined merely by reference to discussions on this subject in the past. The question must be examined in relation to the factors of to-day, and Prof. Myres in his analysis wisely refers us back to the main purposes of any system of education. One main object of education must be to place at the disposal of the next generation the experience accumulated in the past of what takes place around us and of the way in which people react to their environment, leaving it to the coming generation to make what use it chooses of such experience and to develop its own interpretation. This is, of course, the attitude which in the past scientific workers have adopted towards their own discoveries. They have been content for others to make of them what use they would and have been comparatively indifferent to the far-reaching consequences which for good or ill have sometimes flowed from their application. It is this indifference, or the divorce of knowledge from life, that has marred much of our teaching of science and created a prejudice against learning.

The economic consequences of the increased productive powers conferred by mechanical science, the prostitution of scientific knowledge to destructive purposes in armaments, the misuse or abuse of the advantages of modern transport, radio, the cinema for anti-social purposes, and the immense powers for mischief which the application of modern scientific discoveries puts in the hands of careless or vicious individuals in themselves bave brought many to realise that neither science nor society can continue to be unconcerned with the social and moral consequences of scientific research. It is, however, less frequently perceived that brilliant progress in scientific rese $x$ rch and discovery can proceed side by side with the full No. 3291, VoL. 130] deveropment of moral qualities and æesthetic or artistic tastes, and that in fact in the absence of such an environment scientific advance is impeded.

The pursuit of this main objective in education accordingly leads us to realise how closely related are scientific achievement and cultural or moral standards. Prof. Myres pointed out, however, how much more closely they are related in the second main objective of education, the training of the growing generation in the use of knrwledge. This involves the development of human qualities and individualism, the teaching of self-consciousness and of control of oneself, individually and in relation to others. This aspect of knowledge or information is often overlooked, and results in the rigid distinction between the natural sciences and the humanities which has worked so much mischief in education. The human scienceshuman biology, psychology, and statistical economics-form a coherent system and are a fitting subject of scientific study, while moral, political, economic and æsthetic subjects have a geographical as well as a historical aspect or distribution. It is only when the geographical distribution is taken into account that the humanities come into a right relation with life. Individuals and societies alike have a geography and a historical geography as well as a biography, and this inevitably wears thin the distinction between science and the humanities.

Moreover, the distinction between pure and applied science rests on essentially the same factors. So long as they are concerned with problems which have a systematic solution independent of local or temporary conditions, even agriculture and engineering are in effect pure sciences. It is only when they are taking account of local or temporal factors that they become 'applied', and perhaps one reason why so much is at present expected from the engineer is that the liberal traditions of the engineering profession make full allowance for distribution considera. tions. Accordingly, it should be obvious that a systematic science can only be one factor in education for life. It stands apart from the central mass of knowledge and needs supple. menting. Similarly a so-called human science has little value when it becomes systematised and ceases to reveal something significant about man

We may humanise the teaching of a systematic science by devoting more attention to its historical growth and regional applications, as is seen in the growing use of anthropology in the administration 
and education of the backward races. We may clarify and intensify the teaching of the humanities by a firmer distinction between their systematic aspect and those historical and regional reconstructions which alone can set the present civilisation in an intelligible perspectrve. In so doing we should undoubtedly increase the effectiveness of the training we give as a preparation for life, but such teaching and training demand a priori an adequate vision on the part of those giving it. They must themselves have put their minds accurately and intelligently on the facts and situations they have to face.

It is the general absence of an adequate scientific outlook with all that it connotes-the willingness to accept change, the capacity to explore new situations, and to develop appropriate methods undeterred by prejudice or preconceived ideasthat is our gravest danger to-day. To that outlook there must be joined those moral qualities, sincerity of purpose, loyalty to truth, patience, courage, humility, unselfishness and the capacity to work with others, of which neither the philosopher nor the scientific worker has a monopoly and which both have demonstrated can be consistent with the exercise of the greatest intellectual gifts.

The clash between science and the humanities or the classics is long since out of place. The noblest resources of both are needed in the task before us if true are to be sifted from false values. Means must be found of making accurate knowledge of the facts of the universe eloquent and understood of all, and equally the moral consciousness of mankind must be roused to use his knowledge to great purposes. It is only as men are willing to face the full facts of the situation, to develop new methods where they may be called for, to renounce on occasion deeply embedded habits or even ways of thought and take up the challenge of alventure which sciert fic advance flings down to them, that we can hope to emerge from our present difficulties, and handle successfully the many problems presented by an age of mechanism with its concomitant leisure.

For the planning and national planning thus involved for the full exploration and interpretation of the phenomena of social life, scientific outlook and method must be harmoniously linked with a vision of humanity, a sense of values, of order and of beauty which mankind has learnt to find in the individual experience or biography recorded in the humanities in great literature and art.

\section{The Origin of Mammals}

The Mammal-Like Reptiles of South Africa : and the Origin of Mammals. By Dr. Robert Broom. (Issued under the auspices of the Carnegie Corporation of New York, and the Research Buard, Union of South Africa.) Pp. xvi+376. (London: H. F. and G. Witherby, 1932.) $25 s$. net.

FOR many years the fossil reptiles found in the Karroo rocks of South Africa have excited great interest because they seem to include the ancestors of mammals, or at least show how some of the early reptiles may have passed into mammals. They date back to the Permian and Triassic periods, when mammals and birds must have had their beginning; and many of them are in so remarkable a state of preservation as whole skeletons that they are most satisfactory for study. Nearly all, however, are described in small scattered papers, and some are so strange that they have been interpreted in different ways at different times by various authors, so that it is not easy to obtain a good idea of the interesting phase of reptilian evolution which they represent. Dr. Broom has thus done good service to science by preparing an authoritative summary of our present knowledge of the subject, to which he himself has contributed the greater share during the past thirty years. With the aid of a grant from the Carnegie Trust he has published a handsome volume, which will be eagerly studied by all who are interested in current biological problems.

The Karroo rocks seem to have been formed at the mouth of a great ziver which spread its mud over what is now South Africa for many millions of years. There were desert regions around, and most of the sandstones originated from masses of blown sand. The area was sinking, so that an immense thickness of deposits accumulated, and great changes in the reptile life are observable in the successive layers or zones. Dr. Broom briefly enumerates these changes, and shows how some of the latest Karroo reptiles are the most mammal. like, while some of the earliest are most similar to the amphibians which were presumably their ancestors. There is, however, scarcely any trace of these ancestors in South Africa, for the lowest Karroo rocks, so far as known, rarely contain remains of vertebrate animals.

The greater part of Dr. Broom's book naturally consists of a technical systematic account of the various genera and species, which are arranged in

$$
\text { No. 3291, VoL. } 1307
$$

